AperTO - Archivio Istituzionale Open Access dell'Università di Torino

\title{
European guidelines for workplace drug testing in urine
}

\section{This is the author's manuscript}

Original Citation:

\section{Availability:}

This version is available http://hdl.handle.net/2318/1731200

since 2020-02-26T12:13:58Z

Terms of use:

Open Access

Anyone can freely access the full text of works made available as "Open Access". Works made available under a Creative Commons license can be used according to the terms and conditions of said license. Use of all other works requires consent of the right holder (author or publisher) if not exempted from copyright protection by the applicable law. 


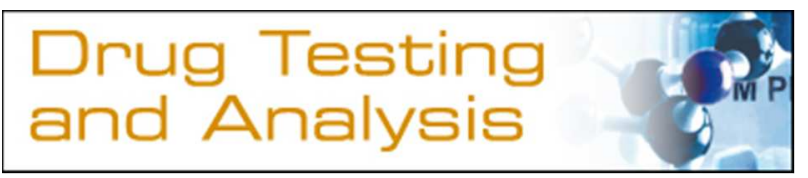

\section{EUROPEAN GUIDELINES FOR WORKPLACE DRUG TESTING IN URINE}

\begin{tabular}{|c|c|}
\hline Journal: & Drug Testing and Analysis \\
\hline Manuscript ID & DTA-16-0278.R1 \\
\hline Wiley - Manuscript type: & Testing Guidelines \\
\hline Date Submitted by the Author: & 09-Feb-2017 \\
\hline Complete List of Authors: & $\begin{array}{l}\text { Taskinen, Sanna; VITA Healthcare Services Ltd, VITA Laboratory } \\
\text { Beck, Olof; Karolinska Institutet, Department of Laboratory Medicine; } \\
\text { Karolinska universitetslaboratoriet, Department of Clinical Pharmacology } \\
\text { Bosch, Tessa; MaastadLab, Department Clinical Pharmacology \& } \\
\text { Toxicology, Hospital Pharmacy } \\
\text { Brcak, Michaela; Greiner Bio-One GmbH } \\
\text { Carmichael, Duncan; AgriYork } 400 \text { Limited } \\
\text { Fucci, Nadia; Institute of Public Health, Section of Legal Medicine, } \\
\text { Università Cattolica del S.Cuore } \\
\text { George, Claire; Alere Toxicology Plc } \\
\text { Piper, Mark; Randox Testing Services } \\
\text { Salomone, Alberto; Centro Regionale Antidoping, } \\
\text { Schielen, Wim; ELDC BV / BeterVee BV } \\
\text { Steinmeyer, Stefan; Dräger Safety AG \& Co. KGaA } \\
\text { Weinmann, Wolfgang; Universitat Bern Institut fur Rechtsmedizin, } \\
\text { Medizinische Fakultät }\end{array}$ \\
\hline Keywords: & guidelines, workplace drug testing, EWDTS, urine \\
\hline Abstract: & $\begin{array}{l}\text { These European Guidelines for Workplace Drug Testing in Urine have been } \\
\text { prepared and updated by the European Workplace Drug Testing Society } \\
\text { (EWDTS). The first version of these urine guidelines was published in } 2002 \text {. } \\
\text { During these years the guidelines have been followed by many laboratories } \\
\text { in different European countries and their role has been essential } \\
\text { particularly in countries lacking legislation for workplace drug testing. In } \\
2014 \text { EWDTS started a guidelines updating project and published new } \\
\text { version of the urine guidelines in } 2015 \text {. Here we represent this new } \\
\text { updated version of the urine guidelines. The European Guidelines are } \\
\text { designed to establish best practice procedures whilst allowing individual } \\
\text { countries to operate within the requirements of national customs and } \\
\text { legislation. The EWDTS recommends that all European laboratories that } \\
\text { undertake legally defensible workplace drug testing should use these } \\
\text { guidelines as a template for accreditation. }\end{array}$ \\
\hline
\end{tabular}




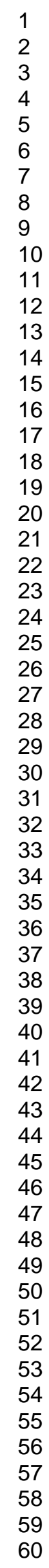

SCHOLARONE $^{\text {th }}$

Manuscripts

http://mc.manuscriptcentral.com/dta 


\section{INTRODUCTION}

The European drug situation has been in constant change during last years. European Monitoring Centre for Drugs and Drug Addiction (EMCDDA) has published current information about drug situation in Europe in European Drug Report 2015 [1]. The availability of new psychoactive substances has increased on drug market. These drugs mimic the effects of established controlled drugs and include substances that are not controlled under drug laws. EU countries have been forced to find ways to quickly adapt of update their legislation in front of this situation. The majority of these new psychoactive substances are synthetic cathinones and synthetic cannabinoids. Also established drugs have been increased according to the seizures. The most commonly used drug in Europe is cannabis, followed by cocaine, amphetamines and MDMA. [1] [2]. According to EU Drug strategy 2013-2020, there is also an increasing trend towards poly-substance use like combination of alcohol, prescribed controlled medication and illicit drugs. [3]

It is estimated that over 80 million adults in the European Union have tried illicit drugs at some point in their lives [1]. Drugs are involved in all areas of life, also in workplaces where they cause a serious problem for a significant proportion of the working population. Drug use ranges from single experimental use to habitual and dependent use. [4] European Agency for Safety and Health at Work has published a report of performance enhancing drugs, which are used by workers and students under the increasing pressure of demands and efficiency at workplaces and during studies [5].

The main reasons for testing employers according to the employees are to avoid health problems and reduced performance of employers, increased sick leaves and work accidents, possible damage to equipment and products and risk for company reputation [4]. Nowadays also data security of a company is a high priority.

However, there are still European counties where workplace drug testing is not allowed. Also legislation for drug testing is still lacking in many countries. Testing becomes topical and rises to headlines especially after bigger accidents. The tragedy of German Wings contributed European aviation safety agency (EASA) to publish rapidly an action plan for the implementation of the Germanwings Task Force recommendations, which included also drug and alcohol testing program [6].

There are mainly three different types of testing at workplaces. In pre-employment testing an employer is tested for drugs before starting working or signing a contract of employment. In random testing any employer may be forced to be tested anytime and it is 
not informed beforehand. In principle, in pre-employment testing and in random testing the employer is not suspected for using drugs. Third kind of situation for drug testing is when an employer is suspected of being under the influence of drugs at the workplace. During a possible rehabilitation program follow up testing is usual. The practices and legislation dealing with all these kind of testing types differ a lot between different countries in Europe. In addition, all types of testing are not allowed in all countries. For different types of testing also different sample matrixes are appropriate, which are mainly urine, oral fluid, hair and blood. Most of the European countries are still lacking legislation for workplace drug testing. There has been a strong demand for a common guideline to unify e.g. the practices of sample taking, test analyses, quality and interpretation of the results. The first guideline of European workplace drug testing society (EWDTS) was published in 2002 for urine. In 2014 EWDTS started a guideline updating project, which was completed in autumn 2015.

Main changes in the new version of the guideline comparing to the former version were:

- New index and structure, which is now similar to the EWDTS guidelines for oral fluid [7] and hair [8]

- In accreditation requirements also the standard EN ISO 15189 in addition to EN ISO/IEC 17025 is accepted. However, method validation should be performed according to the requirements of EN ISOIIEC 17025.

- The guideline is relevant to laboratory-based testing only. It is recommended that point of collection testing (POCT) devices used should come with national of international approvals.

- Urine collection procedure is described more in detail.

- Descriptions of key functions and degrees of laboratory personnel is shortened, while it is covered by accreditation. Specimen collectors do not have to be health care professionals.

- Requirements for identification of analytes and confirmation of results more in detail.

- New substances were added to the list of recommended substances to be tested taking into account current drug situation in Europe. It was not reasonable to give a certain minimum list of substances to be tested because of different drug situation in different countries. Laboratories should be aware of current drug situation in their country and advise the customers to choose an appropriate drug panel.

Page $\mathbf{2}$ of $\mathbf{4 4}$ 


\section{General}

\subsection{Introduction}

These guidelines represent an overview of the best practice for European laboratories providing urine workplace drug testing services to maintain the legal defensibility of a drug test when tested by either an employment tribunal or a court of law. They are designed to ensure that the entire drug testing process is conducted to give accurate and reliable information about a donor's drug use.

\subsection{Objectives}

- To provide a common framework for European providers of urine workplace drug testing services.

- To promote standards by providing guidelines which are accepted at a European level.

- To ensure that the processes undertaken are capable of legal scrutiny.

- To provide safeguards to protect the dignity of the specimen donors and the validity of the specimen.

- To define common quality assurance and quality control criteria for laboratories that are capable of being accredited by an external body.

- To ensure that the entire drug testing process is conducted to give accurate and reliable information about drug use of the donor.

Page 3 of $\mathbf{4 4}$ 


\subsection{Scope}

These guidelines consider the three key stages of the workplace drug testing process.

- Specimen collection: Obtaining the urine specimen from the donor

- Laboratory analysis: Analysis of the sample for the presence of drugs

- Interpretation: Review and interpretation of the analytical results

\subsection{Service Provision}

Where a service provider is contracted to deliver all the stages, they must ensure that the minimum criteria in this document are met in all the key areas. In those instances where a customer may undertake some stages of the process within their own organisation (e.g. specimen collection or interpretation), the service provider has a 'duty of care' to ensure that the customer understands the full implications of the drug testing process.

The service provider does not have the authority to make decisions regarding the fitness for work of any individual being tested. It is recommended that any issues related to fitness for work be referred to the company's medical representative.

\subsection{Drug testing in Context}

It should be explained to any purchaser of a laboratory drug testing service that drug testing should form part of an overall drug policy, which the purchaser has agreed with his employees and should have in place before testing is initiated.

The service provider should have an effective company drugs policy in place. The policy may include drug testing of the staff involved in the analysis and reporting of workplace drug testing results.

\subsection{Outline of drug testing process}

\section{Specimen collection}

Urine specimens for legally defensible drug testing need to be collected under circumstances which respect the dignity of the individual whilst ensuring that the specimen is freshly voided.

Suitable records must be made when the specimen is collected to document that the specimen collected and the specimen received by the laboratery is one and the same.

Page 4 of $\mathbf{4 4}$ 
This is the first link in the chain of custody process which, when reconstructed at a later date, can be used to document that the final result belongs to the specimen collected.

\section{Analysis}

When the specimen is received at the laboratory, checks on the integrity (e.g. colour, odour, etc.) of the sample are carried out. Providing the specimen passes the integrity checks a portion of the specimen is taken and screened for the presence of drugs and sample validity. If the screen results are all negative no further analysis is necessary.

However if the screen tests carried out indicate the possible presence of a drug (above a predefined cut-off level) a confirmation test to prove or disprove the presence of the drug or drug metabolite indicated by the screening test must be carried out on another portion of the specimen.

When a negative result is obtained, either after the screen or confirmation test, it can be reported to the customer. Positive results may require interpretation.

\section{Interpretation}

A laboratory positive result may be due to other reasons than intake of illicit drugs (i.e. prescribed or over-the-counter medication or dietary causes). It requires interpretation that is best carried out by the laboratory toxicologist in conjunction with a qualified medical practitioner who can consult both with the donor and the donor's medical practitioner.

\section{Record keeping}

Suitable records must be made during the analytical process to document that the specimen received by the laboratory and the specimen, about which the final report is written, are one and the same. All samples which prove positive for the presence of drugs and all records of the analytical process, must be kept for an agreed period of time or according to the national legislation to allow for any challenges to be made regarding the findings.

If the customer requires an independent toxicological review, the laboratory must make available, if requested, the analytical data upon which it based its final report. 


\section{Urine Collection}

\subsection{Introduction}

This is the first link in the chain of custody process which, when reconstructed at a later date, can be used to document that the final result belongs to the specimen collected.

The collection process must be carried out by someone formally assessed as competent and authorised to carry out the collection. Standard Operating Procedures (SOPs) must be written for the collection process, the storage of collection devices, the training of Collecting Officers and the shipping of the collected specimen to the laboratory. These procedures must be followed precisely.

Collection procedures must cover the following aspects:

- Privacy and security of the specimen collection site

- Steps to ensure that the specimen collection is supervised.

- Steps to protect against tampering and adulteration

- Identification of the donor giving the specimen

- Evidence of the written informed consent of the individual to the analysis of the specimen (an example is given in Appendix B).

- Disclosure of recent medication, or evidence that the individual was advised of the significance of recent medication.

- All information is considered as confidential.

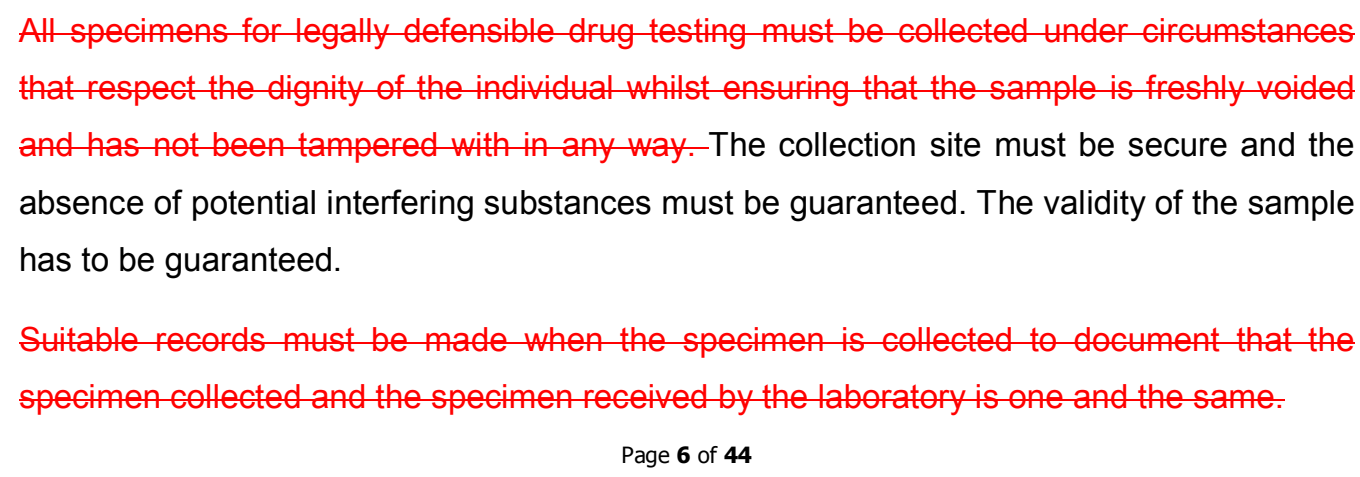
absence of potential interfering substances must be guaranteed. The validity of the sample has to be guaranteed.

Suitable records must be made when the specimen is collected to document that the specimen collected and the specimen received by the laboratory is one and the same. 
Where the customer takes responsibility for the collection process, the service provider has a duty of care to ensure that these guidelines are understood.

\subsection{Personnel}

Specimens must be collected by suitably trained personnel (Collecting Officers). Although no health care professional education is required, a documented training, which includes a demonstration of competence, must be undertaken before collections are performed.

The training must include, at a minimum, instructions on the following:

- The collection process

- The storage and transport conditions of samples

- The chain-of custody process

- Troubleshooting (i.e.e.g. how to deal with issues like refusal of the test, insufficient specimen, suspicion of tampering of the specimen)

- The responsibility of the collecting officer for maintaining donor privacy, confidentiality of information, and specimen integrity.

- Ethical issues, especially regarding the declaration by the donor of the present use of prescribed and over-the-counter medications.

On successful completion of collector training a person may begin performing collections.

\subsection{Urine Collection Kits}

The specimen collection kit should comprise the following components:

- Chain of custody form.

- A unique identifier that links the chain of custody form and specimen bottles.

- Collection cup, demonstrably clean and unused.

- Temperature measurement device.

- At least two specimen bottles (A and B), demonstrably clean and unused.

- Tamper-evident seal for each bottle.

- Packaging components that satisfy current postal and courier regulations.

\subsection{Chain of Custody Form}

The minimum information required on the Chain of Custody Form is:

Page $\mathbf{7}$ of $\mathbf{4 4}$ 
- Unique identification to link the form to the specimen bottles (typically a barcode label or code number assigned to the specimen).

- Information uniquely identifying the donor.

- Evidence that the donor identity has been confirmed.

- Evidence that the donor has given informed consent for the specimen to be tested.

- Date, time and place of collection.

- Names and signatures of all individuals who had custody of the specimen during the collection process.

- Any medication prescribed or non-prescribed that may have been taken in maximum two weeks prior to the specimen being collected.

- Copies for donor, employer $\underline{M R O}$ and laboratory.

\subsection{Urine Collection Procedures}

The guidelines give the current best practice for the collection of urine specimens for analysis. A detailed example of urine collection protocol is in appendix A.

The procedures must cover the following aspects:

- Identification of the individual giving the specimen.

- Sufficient information given to the donor about the meaning and content of the drug test to enable informed consent to be given to providing a sample for analysis.

- Privacy and security of the specimen collection site.

- Steps to ensure that the specimen is freshly voided.

- Steps to protect against tampering and adulteration.

- Splitting the specimen into two specimen bottles (A and B).

- Situations to discard a sample and collect a new one (see Appendix A).

- Evidence of the written informed consent of the individual to the analysis of the specimen (see Appendix B).

- Disclosure of recent medication, or evidence that the individual was advised of the significance of recent medication. 


\section{Laboratory Organisation}

A Quality Management System of the organization / laboratory is required via accreditation according to EN ISO/IEC 17025 and/or EN ISO 15189 in fields of forensic toxicology and/or workplace drug testing analysis.

All personnel must have contracts with the institution (Laboratory Organisation) which they work for and every person must have agreed to the "confidentiality policy" of the institution (in written form).

\subsection{Personnel}

All personnel should adhere to the requirements of EN ISO/IEC 17025 and/or EN ISO 15189 International Standards and as such, only staff who are suitably qualified and whose competence has been formally assessed can work within the laboratory. The laboratory must maintain accurate job descriptions for managerial, technical and key support personnel involved in the analytical tests.

The laboratory must keep records that establish the individual's qualifications I competency for all functions performed. The individual's file must include an up-to-date curriculum vitae listing educational qualifications and previous employment experience, training and competency assessment records for the current tasks performed. Personnel performing specific tasks shall be qualified on the basis of appropriate education, training, experience and/or demonstrated skills, as required.

All laboratory personnel must have received training in Health and Safety issues, the Control of Substances Hazardous to Health (COSHH) Regulations and other relevant legislation.

The key functions outlined below are identified as the minimum requirement for a laboratory to maintain EN ISO/IEC 17025 and/or EN ISO 15189 accreditation for the provision of workplace drug testing services and/or forensic toxicology. It is acceptable for individuals to have responsibility to carry out more than one role. By virtue of the laboratory's accreditation, it can be accepted that the appropriate qualifications for each role are in place.

NOTE: Role titles may vary between organisations, but the responsibilities will remain the same.

Page 9 of $\mathbf{4 4}$ 


\subsection{Laboratory Security}

Drug testing laboratories must have a robust security system to ensure that no unauthorised personnel gain access to the laboratory processes or to areas where samples or records are stored as mentioned in EN ISO/IEC 17025 and/or EN ISO 15189. Unescorted access to these secured areas must be limited to authorised individuals. The laboratory must maintain a record that documents the entry and exit of all visitors to the secured laboratory areas.

The laboratory must maintain a record of all staff who are authorised to enter the secure laboratory areas. This list must be reviewed and updated on a regular basis.

Specimen bottles must be retained within the secure laboratory area until the disposal date.

\subsection{Laboratory Head}

There must be one person who has overall responsibility for the professional, organisational, educational, and administrative activities of the drug testing facility.

This person is responsible for the day-to-day management of the drug testing laboratory. Some of the functions may be delegated to other appropriately qualified personnel but the overall responsibility for any delegated functions will remain with the designated Laboratory Head (typically the Laboratory Supervisor).

\subsection{Authorising Scientist}

A person responsible for the review and certification of pertinent data and quality control results, prior to release of accurate and reliable analytical results.

\subsection{Laboratory Analyst}

A person responsible for undertaking the day-to-day analytical procedures.

Page 10 of 44 


\subsection{Toxicologist}

A person responsible for interpreting a toxicological analytical result for the customer or the customer's designated Medical Review Officer.

\subsection{Expert Witness}

A person to present evidence to administrative or disciplinary proceedings that are based on analytical results reported by the laboratory.

\subsection{Quality Manager}

A person responsible for quality assurance within the laboratory organisation.

\subsection{Other Personnel}

Other technical or non-technical staff who must have the necessary training and skills for the tasks assigned.

\section{Laboratory Analysis Procedures}

\subsection{Process}

When specimens are received at the laboratory, initial checks on the specimen's chain of custody and appearance are carried out. If the specimen passes these checks a portion of the specimen in bottle " $\mathrm{A}$ " is taken and goes through initial screening tests for the presence of drugs. Further testing of sample validity may also take place at this point.

If the screening results are all negative (below a pre-defined cut-off level) no further analyses are necessary.

However, if the screening tests carried out indicate the possible presence of a drug (above a pre-defined cut-off level) a confirmation test to prove or disprove the presence of the drug or drug metabolite indicated by the screening test must be carried out on another portion of the specimen.

The screen-only presumptive positive test is not considered to be legally defensible, but may report preliminary presumptive positive results as local legislation allows. In the report it has to be mentioned that preliminary presumptive positive result may be false positive 
and requires confirmation.

If the first analysis is performed by a confirmation-level analysis (mass spectrometry), the positive findings have to be retested with another portion of the specimen.

\subsection{Chain of Custody}

Laboratories must use chain of custody procedures to maintain control and accountability of specimens and aliquots from receipt through completion of testing, reporting of results, during storage, and continuing until final disposal of specimens and aliquots.

Chain of custody records must be maintained on paper or in computerised form.

\subsection{Specimen receipt}

The laboratory should receive at least two sealed specimen bottles and a corresponding chain of custody form.

At least one of these (referred to, in this document, as the "B" bottle) must be retained unopened and stored in conditions that reflect the storage of the specimen under test (referred to, in this document, as the "A" bottle).

When a sample is received in the laboratory:

- Incoming orders and specimens must be registered by the laboratory.

- Incoming specimens are immediately checked regarding completeness, intactness and suitability for testing.

- Its packaging must be examined for evidence of tampering in transit.

- The information on the specimen bottles within the package must be compared with the information on the accompanying chain of custody form.

- Any discrepancies must be noted and, where appropriate, reported immediately to the customer. Some minor discrepancies may be tolerated in the documentation without termination of the analysis. These must be agreed with the customer prior to analysis and should be documented.

- Appendix $C$ lists examples of fatal flaws in the chain of custody and is provided for guidance. Flaws of this nature would normally result in the specimen not

Page 12 of 44 
being tested.

\subsection{Sample processing}

Separate representative portions (aliquots) of the specimen in bottle 'A' will be used for the screening and confirmation tests. The sample preparation should follow the standard operating procedure and the manufacturer's instructions for the collection system being used. Aliquots must be taken in such a manner that excludes the possibility of contamination.

Short term storage: samples that are not currently undergoing analysis must be refrigerated at $2-8^{\circ} \mathrm{C}$. Stability has to be investigated and appropriate measures undertaken to ensure the sample is valid for the analysis.

The $A$ and the $B$ specimens must be stored under identical conditions.

The quality control requirements in section $\underline{6} 7$ must be satisfied when conducting either screening or confirmation tests, either on single samples or samples grouped in batches.

\subsection{Urine Validity Testing}

The aim of validity testing is to demonstrate that the sample submitted for analysis is urine. The validity of the sample must be checked either before or during the screening process. Creatinine should always be analysed. The laboratory may also test for $\mathrm{pH}$, nitrite, other adulterants or use tests to check the adequate functioning of the antibody in the immunoassay.

\section{Determination of the creatinine concentration}

- If the creatinine concentration is less than or equal to $2.0 \mathrm{mmol} / \mathrm{L}(226 \mathrm{mg} / \mathrm{l})$, the specific gravity must be determined. Acceptable values for specific gravity are $1.001-1.020$.

- Samples with creatinine results within the range $0.5-2.0 \mathrm{mmol} / \mathrm{L}(56-226 \mathrm{mg} / \mathrm{l})$ and specific gravity results within range, should be reported as dilute. Because dilution of urine may cause false negative results, a comment should be added to negative drug testing results. Specimens which screen positive will be confirmed normally and reported if confirmed positive (at or over the pre-defined cut-off value). 
Measurement of $\mathrm{pH}$

- Results within the range 4-9 are deemed to be within a normal range. Results less than 4 or greater than 9 should be considered to be adulterated. Samples falling outside this range should be reported as e.g. "Specimen validity failed".

- Specimens with $\mathrm{pH}$ values outside the normal range which screen positive will be confirmed normally and reported if confirmed positive (at or over the pre-defined cut-off value). Negative drug testing results should not be reported.

\section{Nitrite test: if the nitrite concentration is determined}

- A nitrite level equal to or above $500 \mu \mathrm{g} / \mathrm{mL}$ is conclusive proof of an adulterated sample. The result should be reported as e.g. "Specimen validity failed".

- Specimens with nitrite concentrations above this level which screen positive will be confirmed normally and reported if confirmed positive (at or over the pre-defined cut-off value). Negative drug testing results should not be reported.

\section{Testing for other adulterants}

- If other tests indicate that the sample has been adulterated, or is otherwise unsuitable for analysis then it should be reported as e.g. "Specimen validity failed"

- This remark is also reported when the specimen does not fall under the criteria of $\mathrm{pH}$, creatinine or nitrite above, yet is still not suitable for testing. This can be due to an unidentified interferent or poor specimen quality such as turbidity.

Page 14 of 44 


\section{Analytical Methods and Validation}

\subsection{Acceptable Screening Techniques}

Following methods are accepted e.g.: These methods only may be used:

- Immunoassays

- Gas Chromatography

- High Performance Liquid Chromatography

- All chromatographic techniques coupled to mass spectrometry.

- Capillary Zone Electrophoresis

\subsection{Laboratory Screening Tests}

The initial screening test must shall be based on one acceptable use an appropriate technique (see 5.1). The assay test using the selected technique-must be validated prior to its use.

Recommended maximum screening cut-off concentrations for workplace drug testing are listed in Table 2. These recommended cut-off concentrations may be subject to change reflecting advances in technology and knowledge.

Cut-off concentrations for substances not indicated in Table 2 will need to be agreed with the customer taking into account the performance of the assays to be used and the pharmacokinetics of the drugs involved.

All screening test results must be reviewed with regard to the results of the validity tests performed.

Specimens that test negative on all the initial screening tests and pass the validity tests must be reported as negative and the specimens can be disposed of as agreed with the customer. Specimens that test negative on all the initial screening tests but fail the validity tests may be further investigated to determine the reason why.

The presumptive presence for any drug following the initial preliminary screen must have the presence of the drug or drug metabolite confirmed (refer to section 6.4 Confirmation Tests). If the first analysis is performed by a confirmation-level analysis (massspectrometry), the positive findings have to be confirmed and quantified by reanalysis with another portion of the specimen. 


\subsection{Standardisation of Laboratory Screening Assays}

All assays must be calibrated against appropriate standards by following laboratory protocols based on the manufacturer's recommendations or validated alternatives.

The assay must be calibrated against one named compound, and the cross-reactivity to other related compounds must be determined.

The customer must be informed of the limitations of the tests.

\subsection{Confirmation Tests}

The presence of the drugs indicated by a positive screening result must be confirmed using a chromatographic technique in combination with mass spectrometry (e.g. GC-MS or LC-MS). If the first analysis is performed by a confirmation-level analysis (mass spectrometry), the positive findings have to be confirmed and quantified by reanalysis with another portion of the sample.

All confirmations must be quantitative. The customer must be informed of the compounds detected in the confirmation tests.

Recommended maximum confirmation cut-off concentrations for workplace drug testing are given in Table 3 .

Confirmation cut-off concentrations may be subject to change as advances in technology or other considerations warrant identification of substances at other concentrations. When a sample is tested for substances not indicated in Table 3, the

cConfirmation cut-off levels for substances not indicated in Table 3 must be agreed with the customer taking into account the performance of the assays to be used_(i.e. limit of detection and limit of quantification) -and the pharmacokinetics of the drugs involved (i.e. different metabolites and their detection times):-

Specimens that are below the agreed cut-off concentration must be reported negative. No further testing for drugs will be undertaken and the specimens must be discarded.

Specimens that contain drugs and/or metabolites at concentrations greater than or equal to the agreed cut-off level must be reported as positive.

Laboratories must adhere to national and international guidelines that specify additional criteria for chromatographic and mass spectral acceptability. 


\subsection{Validation}

All methods must be validated and their suitability for intended purpose must be evaluated in accordance with EN ISO/IEC 17025. Laboratories accredited according to EN ISO 15189 should produce evidence of adequate method validation and certificate of participation to Proficiency Test and External Quality Assessment.

The following parameters have to be determined at least for quantitative confirmation analyses and whenever possible, for screening analyses: precision, cut-off verification, selectivity, limit of detection, limit of quantification, sensitivity, specificity, stability, measurement uncertainty and matrix effects.

\subsection{Authorisation and Reporting of Results}

Before any laboratory test result is released, the results and chain of custody documentation must be reviewed and certified as accurate and complete by a competent member of staff (analytical validation). At a minimum, the report must include the specimen identification number and the test result (positive/negative) for each specimen submitted.

Reporting must be managed in accordance with EN ISO/IEC 17025 and/or EN ISO 15189 requirements. In addition the cut-off used for the test should be included.

Only drugs that have been confirmed by a recognised confirmation test may be reported as positive.

Specimens that fail integrity or validity tests must be identified to the customer on the report. The laboratory must define and agree the meaning of all terms used in the report to the customer. Results must be transmitted to the customer's designated representative in a manner that will ensure confidentiality of the information. Laboratory results should not be provided verbally. Written or electronic results must be transmitted to the customer's designated representative in a manner that will ensure confidentiality of the information.

\subsection{Long-Term Storage of Specimens}

The laboratory must demonstrate that the long term storage conditions of specimens are adequate to ensure that analytes are stable over the time period required for any re-test Page $\mathbf{1 7}$ of $\mathbf{4 4}$ 
Currently long-term frozen storage $\left(-20^{\circ} \mathrm{C}\right.$ or below) indicates that most positive specimens will remain suitable for any necessary retest.

Unless otherwise authorised in writing by the customer, drug testing laboratories must retain all specimens confirmed positive in properly secured long-term frozen storage for a minimum of 1 year.

Within this one-year period the customer may request the laboratory to retain the specimen for an additional period of time. If no such request is received, the laboratory may discard the specimen after the end of 1 year. The laboratory shall be required to maintain any specimens known to be under legal challenge for a further agreed period. Specimens must be retained within the secure laboratory area until the disposal date agreed with the customer. Negative specimens $(A+B)$ may be discarded as per the laboratory and customer agreed timetable.

\subsection{Records}

The laboratory must maintain and make available for an agreed period, documentation of all aspects of the testing process and chain of custody documentation involved in the generation of a positive result.

The required documentation must include:

- Training and competency records for all individuals authorised to have access to specimens and specimen data.

- Chain of custody forms

- Quality assessment/quality control records

- Standard operating procedures

- All test data (including method validation, calibration curves and calculations for determining test results)

- Maintenance and instrument calibration records

- Reports

- Records of proficiency testing and computer generated data

The laboratory will be required to maintain documents for any specimen under legal challenge for a further agreed period.

Page 18 of 44 
Document control must be managed in accordance with EN ISO/IEC 17025 and/or EN ISO 15189 requirements and records containing details of individuals should be dealt with in line with European Data Protection Legislation.

\section{Quality Assurance and Quality Control}

\subsection{Quality Assurance}

Drug testing laboratories must have a quality management system which encompasses all aspects of the testing process including but not limited to:

- Specimen receipt

- Chain of custody

- Security and reporting of results

- Screening and confirmation testing

- Certification of calibrators and controls

- Validation of analytical procedures

Quality assurance procedures shall be designed, implemented and reviewed to monitor the conduct of each step of the testing process.

The testing laboratory and all screening and confirmation tests used in Workplace Drug Testing must be fully validated and accredited by a recognised external accreditation body. When an unaccredited method is used the customer should be informed accordingly.

\subsection{Quality Control}

Calibrators and controls shall be prepared using either certified drug reference materials or certified standard solutions obtained from where possible two commercial manufacturers and should be appropriate to the matrix. If two manufacturers are not feasible then the controls should be taken from separate lots from the same manufacturer.

The laboratory must retain records to demonstrate that all calibrators and controls are traceable back to primary standards (if available).

The calibrators and controls shall be properly labelled as to content, concentration, date placed in service and expiry date.

Page 19 of 44 
| All standards (e.g. i.e. pure reference materials, stock standard solutions, purchased standards) shall be labelled with the following:

- Date received (if applicable).

- Date prepared or opened or placed in service.

- Expiration date.

- Lot number of drug reference materials.

- Initials of the technicians who has prepared the (in house) calibrator etc.

All data acquired on control samples as well lot number of drug reference materials must be recorded in such a way as to facilitate interpretation of control results and trends.

\subsection{Laboratory Screening Tests}

These are the minimum requirements for the suitable control of all laboratory screening tests.

A system suitability check must be carried out prior to the analysis of samples.

Assays must be calibrated weekly or when quality control samples indicate poor performance.

Control samples at concentrations of approximately $25 \%$ below and above the cut-off concentration for each drug group must be included in every batch of samples. These must be sourced independently from calibrators.

Quality control samples must comprise at least $5 \%$ of the total number of samples in each batch being analysed.

\subsection{Confirmation tests}

These are the minimum requirements for identification of analytes and confirmation of results [91]

\subsubsection{Identification Mass spectrometry coupled to chromatography}

a) Mass spectrometry coupled to a chromatographic separation method is a very powerful combination for identification of an analyte in the sample extract. It simultaneously provides retention time, ion/charge ratios and relative abundance (intensity) data.

Page $\mathbf{2 0}$ of $\mathbf{4 4}$ 
Requirements for chromatography

b) The minimum acceptable retention time for the analyte(s) under examination should be at least twice the retention time corresponding to the void volume of the column. The retention time of the analyte in the extract should correspond to that of the calibration standard (may need to be matrix-matched) with a tolerance of $\pm 1 \%$, for both gas chromatography and liquid chromatography (Figure 1).

Requirements for mass spectrometry (MS)

c) Reference spectra for the analyte should be generated using the same instruments and techniques used for analysis of the samples. If major differences are evident between a published spectrum and the spectrum generated within the laboratory, the latter must be shown to be valid.

d) Identification relies on proper selection of diagnostic (characteristic) ions. The (quasi) molecular ion is a diagnostic ion that should be included in the measurement and identification procedure whenever possible. In general, and especially in single-stage MS, high $m / z$ ions are more specific than low $m / z$ ions (e.g.i.e. $m / z<100$ ).

e) Extracted ion chromatograms of sample extracts should have peaks (exceeding $S / N$ 3:1 of similar retention time, peak shape and response ratio to those obtained from a calibration standard analysed at comparable concentration in the same batch. Shift in retention time should not exceed $1 \%$ compared to calibration standard.

Chromatographic peaks from different selective ions for the same analyte must overlap with each other. Where an ion chromatogram shows evidence of significant chromatographic interference, it must not be relied upon to quantify or identify residues. The ion that shows the best signal-to-noise ratio and no evidence of significant chromatographic interference should be used for quantification.

f) In case of full scan measurement, careful subtraction of background spectra, either manual or automatic, by deconvolution or other algorithms, may be required to ensure that the resultant spectrum of the chromatographic peak is representative. Whenever background correction is used, this must be applied uniformly throughout the batch and should be clearly indicated.

g) Different types and modes of mass spectrometric detectors provide different degrees of selectivity and specificity, which relates to the confidence in identification. General

Page $\mathbf{2 1}$ of $\mathbf{4 4}$ 
| requirements for identification by MS-methods have been published [91] and should be regarded as guidance criteria for identification, not as absolute criteria to prove presence or absence of a compound.

h) The relative intensities or ratios of selective ions (full-scan MS or SIM) or product ions (MS/MS), expressed as a ratio relative to the most intense (product) ion, should correspond to those of the calibration standard at comparable concentrations and measured under the same conditions. Matrix-matched calibration solutions may need to be used. Table 4 indicates the maximum tolerances for ion ratios.

i) The variability of ion ratios should preferably be determined from calibration standards during initial method validation and subsequently during routine analysis. Diagnostic ions should have an ion ratio of $>0.05$ (least/most intense ion).

j) At higher deviation of the relative abundance of a qualifier ion, analysis needs to be repeated. If tolerances still remain beyond acceptance criteria, further investigation of influences of matrix effects or disturbing compound are recommended -such as standard addition experiments or chance of chromatographic system - to verify or to exclude the presence of a compound. In these cases complementary interpretation by an experienced analyst is recommended.

k) For a higher degree of confidence in identification, further evidence may be achieved from additional mass spectrometric information. For example, evaluation of full scan spectra, isotope pattern, adduct ions, additional accurate mass fragment ions, additional product ions (in MS/MS), or accurate mass product ions.

For High resolution (HRMS) the mass resolution shall typically be greater than 10000 for the entire mass range at $10 \%$ valley (which equates to resolving power of $20000 \mathrm{FWHM}$ (full width at half maximum).

For accurate mass measurements (AMM) the instrument mass error in routine mass measurements must be less than $2 \mathrm{mDa}$ and resolution shall typically be greater than 5000 FWHM. For combination of LC with HR-QToF-MS/MS or other mass spectrometric technique with HR-MS/MS the following settings are recommended for mass spectral identification based on a mass spectral library (commercial or home-made):

Page 22 of $\mathbf{4 4}$ 
For HR-QToF-MS/MS analysis a mass resolution of $>10000$ amu with a mass accuracy of $<5 \mathrm{ppm}$ and an isotope ratio comparability of better than $80 \%$ should be used in routine analysis. If comparison to a library is performed with MS/MS spectra, a fit value of $>70 \%$ should be used as a threshold, for identification of compounds. Additionally, $1 \%$ tolerance of LC-retention time is required (see above, e).

I) The chromatographic profile of the isomers of an analyte or any relevant metabolites may also provide evidence. Additional evidence may be sought using a different chromatographic separation system and/or a different MS-ionisation technique.

\subsubsection{Confirmation of results}

If the initial confirmatory analysis does not provide unambiguous identification or does not meet the requirements for quantitative analysis (e.g., ion ratios not in the suspected range, or chromatographic interference), a confirmatory reanalysis of the A-sample is required. This may involve reanalysis of the extract or the sample. In cases where a detection threshold for a drug is exceeded, a confirmatory analysis of a portion of the B-sample may be required by the authorities.

For unusual analyte/matrix combinations, a confirmatory reanalysis is also recommended.

The use of different determination techniques and/or confirmation of qualitative and/or quantitative results by an independent expert laboratory will provide further supporting evidence.

\subsection{External Quality Assessment}

The laboratory must take part in appropriate external quality assessment schemes. When the scheme is not available, the laboratory has to conduct appropriate inter-laboratory testing to ensure appropriate assay performance.

\subsection{Sub-contracting}

Drug testing laboratories should carry out all laboratory work with their own personnel and equipment. If it is necessary to sub-contract, inter-laboratory transfer of samples is performed with strict adherence to chain of custody procedures. The sub-contracted laboratory and its methods used must be accredited by a recognised external accrediting Page 23 of 44 
body and compliant with these guidelines. Analyses undertaken by sub-contracted laboratories must be identified on the test report to the customer.

\section{Interpretation of Results}

A confirmed analytical positive result may be due to medication (prescribed or over-thecounter) or due to dietary causes. An essential part of the drug testing process is the final review of analytical results.

| The interpretation is best carried out by a qualified medical professional (e.g.i.e. Medical Review Officer) or a Toxicologist (depending on the country-specific situation) (See chapter-4ㅁ).

\subsection{Toxicology Review}

It is mandatory that a toxicologist is available to advise the customer and/or Medical Review Officer regarding queries with test results.

\subsection{Medical Review}

The Medical Review Officer (MRO) is a medical physician with responsibility for interpreting laboratory results together with a toxicologist. Depending on the countryspecific situation a medical physician usually has greater access to medical records than a toxicologist and may therefore be in a better position to provide interpretation of positive analytical results.

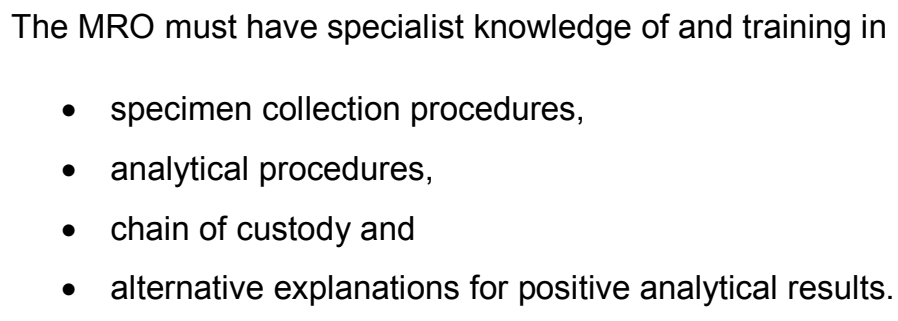

The MRO can issue a negative report for a positive analytical result if the test result is likely to be due to the use of declared medication, or a valid alternative medical explanation has been found.

Page 24 of 44 
The service provider may provide access to an independent medical review service.

\section{Challenges to Drug Test Results}

In situations where there is a challenge to the results of a confirmed positive drug test result, the following guidelines must be used.

The B specimen should be released for analysis to a drug testing laboratory accredited by a recognised external accrediting body and working to these guidelines. This release requires authorisation from both the customer/MRO and the donor.

The release must be supported by chain of custody procedures that can withstand legal scrutiny and include information about the findings of the original test (corresponding $A$ specimen) and the cut-offs used for the test.

The original laboratory must retain the residue of the original $A$ specimen and its containers so that they can be compared with the B specimen at a later date if required.

All laboratories that undertake $B$ specimen testing must be able to demonstrate that they can accurately determine the concentration of a drug or metabolite at $50 \%$ of the recommended confirmation cut-off concentration listed in Table 3 (or the cut-off used for the original test, whichever is the lower).

On receipt in the testing laboratory, the B sample should follow chain of custody procedures as outlined. It is recommended that the laboratory should carry out validity checks outlined prior to carrying out the confirmation analysis. Only those drugs/metabolites identified for confirmation testing should be looked for.

The final report on the B specimen must say either that the result was reconfirmed or failed to reconfirm. Confirmation cut-off levels are not to be used as the determinant. There must be no comment on the final report that states whether the sample is positive or negative. 


\section{Appendix A}

\section{Urine Collection Procedure}

(Note: Only formally competence tested and authorised persons may act as collecting officers. Medical qualification is NOT required for collecting officers.)

\section{Collection Site}

Procedures shall provide for a designated collection site to be secure. During the collection process the collection site must be dedicated solely to sample collection and comply with all local health and safety requirements.

The circumstances of the collection site should be arranged so that adulteration of the specimen is prevented as well as possible. To deter the dilution of specimens at the collection site, toilet water colouring agents should be placed in toilet tanks wherever accessible or in the toilet bowl, so the reservoir of water in the toilet bowl always remains coloured. Any other sources of water in the enclosure where urination occurs (e.g. taps, shower) will be secured prior to collection. At the collection site access must be controlled to soap dispenser, cleaning agent, or any other materials that could be used to adulterate the specimen. Also paper towel dispensers, ceiling tiles, or other spaces that could be used to hide adulterants, must be secured during the specimen collection.

\section{Access to Authorised Personnel Only}

Only authorised personnel shall be permitted in any part of the designated collection site when urine specimens are being collected or stored. The donor has the right to be accompanied with a silent witness, but that should not interfere or delay the collection process, nor is the witness permitted to accompany the donor into the enclosure where the urination occurs.

\section{Chain of Custody}

During the collection process chain of custody forms will be completed fully by the collecting officer and donor.

Page 26 of $\mathbf{4 4}$ 


\section{Identification of the donor}

When a donor arrives at the collection site, the collecting officer will request that the donor presents photographic identification and a signature for comparison. If the donor does not have acceptable photographic identification, the collecting officer will obtain a positive identification of the donor by an authorised supervisor or manager within the parent organisation. If the donor's identity cannot be established, the collecting officer will not proceed with the collection.

\section{Informing the donor about the test}

The donor has to be informed about the purpose and the content of the test.

\section{Consent of the donor}

The donor gives his/her consent for urine collection and analysis of drugs by signature. If the donor refuses to give a sample, a note to this effect should be recorded on the form designated for that purpose. Appendix B gives an example of a Donor's Statement of Informed Consent.

\section{Privacy}

Procedures for collecting urine specimens shall allow individual privacy during urination and no observed collection is appropriate in normal cases. Donors have to be treated equally regardless of gender, ethnicity, or any physical impairment. The process should avoid embarrassment but should also be stringent enough to satisfy challenge of the specimen integrity and collection process.

If there is a strong suspicion of specimen adulteration due to not passed specimen validity checks and/or the previous specimen, collected from the donor, was-has been adulterated, the-new specimen can be collected under the direct observation of the collecting officer.

\section{Integrity of the Specimen}

The collecting officer must adopt procedures to minimise the risk of adulteration of the specimen during the collection procedure. The following minimum precautions shall be 
taken to ensure that unadulterated specimens are obtained and correctly identified:

a. The collecting officer will ask the donor to show that their pockets are empty and remove any unnecessary outer garments such as a coat or jacket that might conceal items or substances that could be used to tamper with or adulterate the donor's urine specimen. The collecting officer will ensure that all personal belongings such as a purse or briefcase remain with the outer garments.

b. The donor must wash his/her hands with water only prior to urination with inspection of the hands afterwards by the collecting officer.

c. After washing hands, the donor will remain in the presence of the collecting officer and will not have access to any unregulated source of water, soap dispenser, cleaning agent, or any other materials that could be used to adulterate the specimen.

d. The donor will choose a clean specimen container. The donor may provide his/her specimen in the privacy of a toilet cubicle or otherwise partitioned area that allows for individual privacy. The collecting officer will remain outside the cubicle until the specimen is collected. The donor will be instructed not to flush the toilet until the specimen is handed to the collecting officer.

e. The collecting officer will note any unusual behaviour of the donor on the chain of custody form.

f. Upon receiving the specimen from the donor, the collecting officer will:

- Check the volume of urine in the specimen container

- The sufficient volume is approx. 20 millilitres $(\mathrm{mL})$ or more.

- If the volume is less than $20 \mathrm{~mL}$, the specimen will be discarded and a second specimen will be collected. The donor may be offered a reasonable amount of liquid to drink for this purpose (max 2 times $250 \mathrm{~mL}$ in 1 hour, not to exceed a maximum of 0.5 litre). In these circumstances a donor should normally be able to provide a $20 \mathrm{~mL}$ urine specimen within 2 to 3 hours.

- The samples must not be combined to provide a sufficient volume.

- If the donor fails to provide a specimen within this time period the collecting officer will contact the appropriate authority to obtain guidance on the action to be taken.

- Check the temperature of the urine specimen. 
- The temperature-measuring device used must accurately reflect the temperature of the specimen and not contaminate the specimen. The time from urination to temperature measurement is critical and in no case should exceed 4 minutes.

- The acceptable range of the temperature is $32^{\circ} \mathrm{C}-38^{\circ} \mathrm{C}$.

- A temperature outside the acceptable range is a reason to be suspicious that the donor may have altered or substituted the specimen. Another specimen will be obtained as soon as possible and both specimens will be forwarded to the laboratory for testing.

If there is a strong suspicion of adulteration and/or the previous sample was adulterated the specimen can be collected under the direct observation of a collecting officer.

- Inspect the specimen to determine its colour and appearance for any signs of contaminants.

- Any unusual findings will be noted on the chain of custody form.

- If there is any reason to believe that a donor may have adulterated, altered or substituted the specimen, another specimen will be obtained as soon as possible and both specimens will be forwarded to the laboratory for testing.

If there is a strong suspicion of adulteration and/or the previous sample was adulterated the sample can be collected under the direct ebservation of a collecting officer.

g) Both the donor and the collecting officer will keep the specimen container / specimen bottles in view at all times prior to the urine specimen being sealed and labelled.

h) The specimen is split into a minimum of two specimen bottles. When the specimen is transferred from the specimen container to the specimen bottles, it will be poured and the collecting officer will request the donor to observe the transfer of the specimen and the attachment of the tamper-evident seal/tape on the bottles. The tamper-evident seal ensures that any tampering with the specimen will be evident to laboratory personnel during the laboratory receipt.

i) Direct contact tests (e.g. pH) can only be carried out on the residue of the specimen after the sample has been split and sealed into specimen bottles. 
- The acceptable range of $\mathrm{pH}$ is 4-9. The appropriate $\mathrm{pH}$ measuring device covers the whole $\mathrm{pH}$-range (e.g. $\mathrm{i}$.e.1-14) to be able to measure $\mathrm{pH}$ outside the acceptable range.

- A pH value outside of the acceptable range is a reason to be suspicious that the donor may have altered the specimen. Another specimen will be obtained as soon as possible and both specimens will be forwarded to the laboratory for testing.

a If there is a strong suspicion of adulteration and/or the previous specimen was adulterated the sample can be collected under the direct observation of a collecting

efficer.

j) A minimum of two sealed specimens together with the corresponding chain of custody documentation in a tamper evident container must be dispatched to the laboratory. One bottle will be used for the drug test while the second bottle will remain sealed at the analytical laboratory in case the donor wishes to challenge a positive result.

k) At an appropriate time after the urine specimen has been collected and sealed into the transport bottles the collecting officer will invite the donor to wash his/her hands.

I) The specimen bottle will have an identification label that contains at a minimum the date, the donor's specimen number and the donor's signature/initials. The collecting officer will enter all information on the chain of custody form to identify the origin of the specimen. Both specimen bottles and all pages of the chain of custody will be labelled at the time of collection with a unique identifier.

$\mathrm{m})$ The collecting officer will ask the donor questions relating to the drugs and medicines consumed within a maximum of 14 days prior to the provision of the urine specimen. These questions will be specific and wide ranging covering areas such as medications prescribed or dispensed by a doctor, dentist or hospital department and over-the-counter preparations. All information is written down to the chain of custody form.

n) The donor will be asked to read and sign a statement on the chain of custody form certifying that the specimen identified on the form was in fact the specimen provided by the donor and giving informed consent for the work to be undertaken. Appendix B gives an example of a Donor's Statement of Informed Consent. 


\section{Exceptional situations}

a. The donor is not able to give a sample

The donor may be offered a reasonable amount of liquid to drink for this purpose (max 2 times $250 \mathrm{~mL}$ in 1 hour, not to exceed a maximum of 0.5 litre). In these circumstances a donor should normally be able to provide a $20 \mathrm{~mL}$ urine specimen within 2 to 3 hours. If the donor fails to provide a specimen within this time period the collecting officer will contact the appropriate authority to obtain guidance on the action to be taken.

b. The donor wants to give the sample later The collecting officer must not allow the donor to leave the collection site and come back later to provide a specimen. The collecting officer will contact the appropriate authority to obtain guidance on the action to be taken.

c. Admission of illegal drug use

If the donor admits illegal drug use, this should be noted on the chain of custody form.

\section{Transportation to Laboratory}

Collecting officers will arrange to dispatch the collected specimens to the drug-testing laboratory. The specimens will be placed in containers designed to minimise the possibility of damage during shipment and packed properly to comply with local/international mail and courier regulations for biological specimens. Since specimens and the corresponding

Page $\mathbf{3 1}$ of $\mathbf{4 4}$ 
7 documents are sealed in packages that would indicate any tampering during transit to the laboratory by couriers, carriers, and postal services, usually there is no requirement for documented chain of custody procedures for the transport of the package. 
10 Appendix B

\section{Example of a Donor's Statement of Informed Consent}

I confirm that I have received information about the meaning and content of the drug test. I confirm that I have provided a freshly voided urine specimen to the specimen collector. I have observed the specimen being placed and sealed in the specimen bottles and I confirm that the information on this form and on the specimen labels is correct. I hereby give permission for a minimum of two sealed specimen containers to be sent to the laboratory and I consent that they be tested for evidence of drug use and for tests to be carried out to confirm the validity of the sample. Furthermore, I understand that the results will be communicated confidentially to the employer or a designated representative.

I consent to the above.

Donor's Name (Block Capitals):

Donor's Signature:

Date:

Donor's identifier on the specimen labels (if different from above): 


\section{Appendix C}

\section{Some examples of fatal flaws in the Chain of Custody}

1. A unique identifier (e.g. barcode) mismatches or absent

2. No documentation received with the sample

3. No written consent to test from the donor

4. Seals broken or tampered with on any bottle

5. No seals

6. Only 1 sample received

7. Insufficient sample for complete analysis

8. Leaking sample

9. No collecting officer name and signature on the chain of custody form 


\section{REFERENCES}

[1] European Monitoring Centre for Drugs and Drug Addiction (EMCDDA): European Drug

Report 2015, Trends and Developments available at:

http://www.emcdda.europa.eu/attachements.cfm/att_239505_EN_TDAT15001ENN.pdf

[2] European Monitoring Centre for Drugs and Drug Addiction (2015), New psychoactive substances in Europe. An update from the EU Early Warning System (March 2015),

Publications Office of the European Union, Luxembourg. Available at:

www.emcdda.europa.eu/publications/2015/new-psychoactive-substances

[3] European Monitoring Centre for Drugs and Drug Addiction (EMCDDA): The EUdrugs strategy (2013-20) and its action plan (2013-16) available at:

http://www.emcdda.europa.eu/topics/pods/eu-drugs-strategy-2013-20

[4] European Foundation for the Improvement of Living and Working Conditions, 2012:

Use of alcohol and drugs at the workplace, available at:

http://www.eurofound.europa.eu/observatories/eurwork/comparative-information/use-ofalcohol-and-drugs-at-the-workplace

[5] European Agency for Safety and Health at Work: A review on the future of work:

Performance-enhancing drugs (2015) available at: https:/losha.europa.eu/en/tools-andpublications/publications/future-work-performance-enhancing-drugs

[6] European aviation safety agency (EASA): Action plan for the implementation of the Germanwings Task Force recommendations (1-7 October, 2015) available at: http://easa.europa.eu/download/various/GW_actionplan_final.pdf

[7] European Guidelines for Workplace Drug Testing in Oral Fluid, EWDTS, 2015:

available at http://waw.ewdts.org/ewdts-guidelines.html

[8] European Guidelines for Workplace Drug and Alcohol Testing in Hair, EWDTS, 2015:

available at http://www.ewdts.org/ewdts-guidelines.html

[91] Guidance document on analytical quality control and validation procedures for pesticide residues analysis in food and feed.SANCO/12571/2013-SANCO/12495/2011, Implemented by 01/01/2014, Pages $11=13$. Available at:

http://www.eurl-pesticides.eu/library/docs/allcrl/AqcGuidance_Sanco_2013_12571.pdf, last access $27^{\text {th }}$ January 2017

Page 35 of 44 


\section{[102] COMMISSION DECISION of 12 August 2002 implementing Council Directive} 96/23/EC concerning the performance of analytical methods and the interpretation of results (notified under document number C (2002) 3044) (2002/657/EC) (table 4, page 9).

Available at: http://eur-lex.europa.eu/legalcontent/EN/TXT/PDF/?uri=CELEX:32002D0657\&from=EN, last access $27^{\text {th }}$ January 2017http://eur-lex.europa.eu/legalcontent/EN/TXT/PDF/?uri=CELEX:32002D06578from=EN

[113] GTFCh (01.06.2009):-L. D. Paul, F. Mußhoff, "Richtlinie der GTFCh zur Qualitätssicherung bei forensisch-toxikologischen Untersuchungen". Toxichem Krimtech,

Formatted: Font: Italic 2009, 76 (3), 142-176-, https://www.gtfch.org/cms/images/stories/files/GTFCh Richtlinie For-

Tox Version\%201.pdf, last access $27^{\text {th }}$ January 2017 
Table 1 Definitions

For purposes of these guidelines the following definitions have been adopted:

\begin{tabular}{|c|c|}
\hline Adulteration & See Tampering \\
\hline Aliquot & $\begin{array}{l}\text { A fractional part of a specimen used for testing. It is taken as a sample } \\
\text { representing the whole specimen. }\end{array}$ \\
\hline $\begin{array}{l}\text { Authorising } \\
\text { Scientist }\end{array}$ & $\begin{array}{l}\text { A person who reviews all pertinent data and quality control results in } \\
\text { order to attest to the validity of the laboratory's test reports. }\end{array}$ \\
\hline Calibrator & $\begin{array}{l}\text { A solution of known concentration used to calibrate a measurement } \\
\text { procedure or to compare the response obtained with the response of a } \\
\text { test sample/sample. The concentration of the analyte of interest in the } \\
\text { calibrator is known within limits ascertained during its preparation. } \\
\text { Calibrators may be used to establish a calibration curve over a } \\
\text { concentration range of interest. }\end{array}$ \\
\hline $\begin{array}{l}\text { Chain of } \\
\text { Custody }\end{array}$ & $\begin{array}{l}\text { Procedures to account for each specimen by tracking its handling and } \\
\text { storage from point of collection to final disposal. These procedures } \\
\text { require that the donor identity is confirmed and that a chain of custody } \\
\text { form is used from time of collection to receipt by the laboratory. Within } \\
\text { the laboratory appropriate chain of custody records must account for } \\
\text { the specimens until disposal. }\end{array}$ \\
\hline $\begin{array}{l}\text { Chain of } \\
\text { Custody } \\
\text { Form }\end{array}$ & $\begin{array}{l}\text { A form used to document the procedures from time of collection until } \\
\text { receipt by the laboratory. }\end{array}$ \\
\hline $\begin{array}{l}\text { llecting } \\
\text { ficer }\end{array}$ & A person trained to collect specimens from donors. \\
\hline $\begin{array}{l}\text { Collection } \\
\text { Site }\end{array}$ & $\begin{array}{l}\text { A place where individuals present themselves for the purpose of } \\
\text { providing a specimen for analysis. }\end{array}$ \\
\hline $\begin{array}{l}\text { Confirmation } \\
\text { Test }\end{array}$ & $\begin{array}{l}\text { An analytical procedure to identify and quantify the presence of a } \\
\text { specific drug or metabolite which is independent of the initial test and } \\
\text { which uses a different aliquot, technique and chemical principle from } \\
\text { that of the screen test in order to ensure reliability and accuracy. }\end{array}$ \\
\hline Customer & The organisation requesting the drug testing service. \\
\hline Cut-off & $\begin{array}{l}\text { A concentration level set to determine whether the sample is positive or } \\
\text { negative for the presence of a drug. }\end{array}$ \\
\hline Donor & The individual from whom a urine specimen is collected. \\
\hline Laboratory & The facility providing the analytical services to detect drugs of abuse. \\
\hline $\begin{array}{l}\text { Negative } \\
\text { result }\end{array}$ & $\begin{array}{l}\text { A result reported by the laboratory that indicates that either no drug or } \\
\text { drug metabolite is present in the specimen or that any drug or drug } \\
\text { metabolite present is below the cut-off. }\end{array}$ \\
\hline $\begin{array}{l}\text { Observed } \\
\text { Collection }\end{array}$ & $\begin{array}{l}\text { A donor gives the specimen under the direct observation of the } \\
\text { collecting officer. }\end{array}$ \\
\hline
\end{tabular}

Page $\mathbf{3 7}$ of $\mathbf{4 4}$ 


\begin{tabular}{|c|c|}
\hline $\begin{array}{l}\text { Positive } \\
\text { result }\end{array}$ & $\begin{array}{l}\text { A result reported by the laboratory as positive means that there is } \\
\text { conclusive evidence that a drug or drug metabolite is present in the } \\
\text { specimen tested at a level greater than or equal to the confirmation cut- } \\
\text { off concentration. }\end{array}$ \\
\hline $\begin{array}{l}\text { Quality } \\
\text { control } \\
\text { sample }\end{array}$ & $\begin{array}{l}\text { A sample used to evaluate whether or not an analytical procedure is } \\
\text { operating within pre-defined tolerance limits. }\end{array}$ \\
\hline $\begin{array}{l}\text { Medical } \\
\text { Review } \\
\text { Officer (MRO) }\end{array}$ & $\begin{array}{l}\text { A medical physician responsible for receiving laboratory results from } \\
\text { the drug-testing laboratory who has knowledge of substance abuse } \\
\text { and has appropriate training or experience to interpret and evaluate an } \\
\text { individual's positive test result, in light of declared information. }\end{array}$ \\
\hline Sample & $\begin{array}{l}\text { A representative portion of a specimen submitted used by a laboratory } \\
\text { for testing. }\end{array}$ \\
\hline $\begin{array}{l}\text { Screening } \\
\text { Test }\end{array}$ & $\begin{array}{l}\text { A test to eliminate negative specimens from further consideration and } \\
\text { to identify the presumptive positive specimens that require confirmation } \\
\text { testing. }\end{array}$ \\
\hline $\begin{array}{l}\text { Service } \\
\text { Provider }\end{array}$ & $\begin{array}{l}\text { The organisation contracted to provide the drug testing service. This } \\
\text { may be a laboratory, or a third party providing other elements of the } \\
\text { service, and sub-contracting the tests to another laboratory. }\end{array}$ \\
\hline Specimen & The portion of urine that is collected from a donor. \\
\hline Standard (1) & $\begin{array}{l}\text { A reference material of known purity or a solution containing a } \\
\text { reference material at a known concentration. }\end{array}$ \\
\hline Standard (2) & $\begin{array}{l}\text { An agreed protocol or procedure (EN ISO/IEC } 17025 \text { and EN ISO } \\
\text { 15189) }\end{array}$ \\
\hline $\begin{array}{l}\text { Standard } \\
\text { Operating } \\
\text { Procedure } \\
\text { (SOP) }\end{array}$ & $\begin{array}{l}\text { A written document giving the detailed steps to be followed when } \\
\text { undertaking a particular task (e.g. the analysis of a given drug or drug } \\
\text { metabolite in a urine specimen). }\end{array}$ \\
\hline Tampering & $\begin{array}{l}\text { Any process by which an individual knowingly interferes with (or } \\
\text { attempts to interfere with) the processes of specimen collection, } \\
\text { transport or analysis with the intention of avoiding a legitimate test } \\
\text { result. The actions undertaken can include (but are not limited to) the } \\
\text { addition of water or foreign substances to the specimen, specimen } \\
\text { substitution, damaging bottle seals or packaging and the deliberate } \\
\text { consumption of interfering substances or copious volumes of water } \\
\text { prior to specimen collection. }\end{array}$ \\
\hline Toxicologist & $\begin{array}{l}\text { A person responsible for interpreting a toxicological analytical result for } \\
\text { the customer or the customer's designated Medical Review Officer. }\end{array}$ \\
\hline
\end{tabular}




\section{Table 2 Recommended Substances and Maximum Cut-Off Concentrations for} Screening Tests in Urine

The purpose of the cut-offs' of listed substances is due to a longer detection time/window. It is a recommendation of the upper limit for cut-off concentrations. In the list below, where the value is given, this is the maximum recommended cut-off.

\begin{tabular}{|l|c|}
\hline & $\mathbf{n g} / \mathbf{m L}$ \\
\hline Amphetamines group & 500 \\
\hline Barbiturates & 200 \\
\hline Benzodiazepines group & 200 \\
\hline Buprenorphine & 5 \\
\hline Cannabis metabolites & 50 \\
\hline Cocaine metabolites & 150 \\
\hline EDDP (or methadone) & 100 \\
\hline LSD or metabolites & $(300)$ \\
\hline Opiates (total) & 1 \\
\hline Phencyclidine & 300 \\
\hline Propoxyphene or metabolites & 25 \\
\hline
\end{tabular}

\begin{tabular}{|l|c|}
\hline Cut-off under investigation / discussion: & \\
\hline Gammahydroxybutyrate (GHB) & - \\
\hline Ketamine & - \\
\hline $\begin{array}{l}\text { Other opioids (e.g. oxycodone, hydromorphone, tramadol, fentanyl, } \\
\text { tilidine) }\end{array}$ & - \\
\hline Pregabalin & - \\
\hline Synthetic cannabinoids & - \\
\hline Synthetic cathinones (MDPV etc.) & - \\
\hline Z-Drugs (Zopiclone, Zolpidem, Zaleplon) & \\
\hline
\end{tabular}

Page 39 of 44 
Note:

1. The laboratory has to take into account country-specific differences in the drugpanel they are using.

2. These recommended cut-off values may be subject to change as advances in technology or other considerations warrant identification of these substances at other concentrations.

3. Cut-off levels for substances not indicated in Table 2 will need to be agreed with the customer taking into account the performance of the assays to be used. The toxicologist/ laboratory have to explain the meaning to the customer.

4. When using immunological analyses the differences in cross-reactivity of different substances have to be noted.

5. The laboratory is responsible for remaining aware of local drug trends and has a responsibility to use this knowledge to advise the customer of the most appropriate substances to be included in the drug testing panel.

Page $\mathbf{4 0}$ of $\mathbf{4 4}$ 


\section{Table 3 Recommended Substances and Maximum Cut-Off Concentrations for} Confirmation Tests in Urine

The purpose of the cut-offs' of listed substances is due to a longer detection time/window. It is a recommendation of the upper limit for cut-off concentrations. In the list below, where the value is given, this is the maximum recommended cut-off.

\begin{tabular}{|l|c|}
\hline & $\mathbf{n g} / \mathbf{m L}$ \\
\hline Amphetamines & \\
\hline Amphetamine $(\mathrm{d}+\mathrm{I})$ & 200 \\
\hline Methamphetamine & 200 \\
\hline MDA & 200 \\
\hline MDMA & 200 \\
\hline Other members of the amphetamine group & 200 \\
\hline Benzodiazepines or their metabolites & \\
\hline Alprazolam & 100 \\
\hline Bromazepam & 100 \\
\hline Clonazepam & 100 \\
\hline Diazepam & 100 \\
\hline Flunitrazepam & 100 \\
\hline Flurazepam & 100 \\
\hline Lorazepam & 100 \\
\hline Lormetazepam & 100 \\
\hline Midazolam & 100 \\
\hline Nitrazepam & 100 \\
\hline Nordiazepam & 100 \\
\hline Oxazepam & 100 \\
\hline Phenazepam & 100 \\
\hline Temazepam & \\
\hline Opiates & 100 \\
\hline
\end{tabular}

Page 41 of 44 


\begin{tabular}{|c|c|}
\hline Morphine & 300 \\
\hline Codeine & 300 \\
\hline 6-Monoacetylmorphine & 10 \\
\hline Dihydrocodeine & 300 \\
\hline \multicolumn{2}{|l|}{ Cannabis } \\
\hline Cannabis metabolite (THC-COOH) & 15 \\
\hline \multicolumn{2}{|l|}{ Cocaine } \\
\hline Cocaine metabolite (Benzoylecgonine) & 100 \\
\hline \multicolumn{2}{|l|}{ Methadone } \\
\hline Methadone $(\mathrm{d}+\mathrm{l})$ & 250 \\
\hline EDDP & 75 \\
\hline \multicolumn{2}{|l|}{ Other drugs: } \\
\hline Barbiturates & 150 \\
\hline Buprenorphine or metabolite & 2 \\
\hline LSD or metabolites & 1 \\
\hline Phencyclidine & 25 \\
\hline Propoxyphene or metabolites & 300 \\
\hline \multicolumn{2}{|l|}{ Cut off under investigation / discussion: } \\
\hline Gammahydroxybutyrate (GHB) & - \\
\hline Ketamine & - \\
\hline $\begin{array}{l}\text { Other opioids (at least Oxycodone, Hydromorphone, Tramadol, Fentanyl, } \\
\text { Tilidine) }\end{array}$ & - \\
\hline Pregabalin & - \\
\hline Synthetic cannabinoids & - \\
\hline Synthetic cathinones (MDPV etc.) & - \\
\hline Zaleplon & - \\
\hline Zolpidem & - \\
\hline Zopiclone & - \\
\hline
\end{tabular}


Note:

1. The laboratory has to take into account country-specific differences in the drugpanel they are using.

2. These recommended cut-off values may be subject to changes as advances in technology or other considerations warrant identification of these substances at other concentrations.

3. Cut-off levels for substances not indicated in Table 3 will need to be agreed with the customer taking into account the performance of the assays to be used. The toxicologist/ laboratory has to explain the relevance of the cut-offs to the customer.

4. The laboratory is responsible for keeping abreast of local drug trends and-advising the customer regarding relevant drugs for inclusion in the drug testing panel

5. The Limit of Quantification (LOQ) for each drug has to be no more than $50 \%$ of the confirmation cut-off level.

6. The laboratory has to be able to determine $d$ - and l-amphetamines, if required.

Page $\mathbf{4 3}$ of $\mathbf{4 4}$ 
Table 4 Recommended maximum tolerances for ion ratios using different MS techniques [102, 11 $\underline{3}$ ]

\begin{tabular}{|c|c|c|}
\hline $\begin{array}{l}\text { lon ratio } \\
\text { (least/most intense ion) }\end{array}$ & $\begin{array}{l}\text { Maximum tolerance } \\
\text { (relative) for GC-EI-MS }\end{array}$ & $\begin{array}{l}\text { Maximum tolerance (relative) } \\
\text { for GC-Cl-MS, GC-MS } \\
\text { LC-MS, LC-MS }\end{array}$ \\
\hline$>50 \%$ & $20 \%$ & $20 \%$ \\
\hline$>20-50 \%$ & $20 \%$ & $25 \%$ \\
\hline$>10-20 \%$ & $25 \%$ & $30 \%$ \\
\hline$\leq 10 \%$ & $50 \%$ & $50 \%$ \\
\hline
\end{tabular}

Page $\mathbf{4 4}$ of $\mathbf{4 4}$ 


\section{Figure 1}

$$
\frac{r t_{\text {analyte in sample }}-r t_{\text {analyte in calibrator }}}{r t_{\text {analyte in calibrator }}} \leq 0.01
$$

